\title{
A trace gas technique for measuring clothing microclimate air exchange rates
}

\author{
G. W. CROCKFORD, M. CROWDER ${ }^{1}$, and S. P. PRESTIDGE \\ TUC Centenary Institute of Occupational Health and the Medical Research Council \\ Environmental Physiology Unit, London School of Hygiene and Tropical \\ Medicine, London WC1
}

\begin{abstract}
Crockford, G. W., Crowder, M., and Prestidge, S. P. (1972). Brit. J. industr. Med., 29, 378-386. A trace gas technique for measuring clothing microclimate air exchange rates. The rate at which clothing microclimate air is exchanged for ambient air influences the sensible and insensible heat loss from the microclimate. Factors which influence this air exchange are clothing permeability, wind speed, body movements, clothing design, and fabric properties. The influence of the first four factors has been studied using a trace gas technique for measuring the rate at which microclimate air is exchanged for ambient air. The trace gas technique and the mathematicalmodel describing the loss of the trace gas from the microclimate are described. The technique is shown to have a high resolving power, enabling small changes in the four factors studied to be identified, and as the method is also very quick detailed studies of garment design can be made.
\end{abstract}

One of the functions of clothing is to modify, in a favourable manner, the wearer's microclimate. This is done to a large extent by stabilizing the layer of air next to the body and limiting its exchange with the environment. A complete lack of exchange between the ambient air and that trapped by the clothing is, however, undesirable as the body is losing water as insensible perspiration all the time, and this water would accumulate in the clothing and adversely affect comfort and thermal insulation. A limited and controlled exchange of air between the microclimate and the environment is therefore required. The permeable conventional fabrics used in ordinary clothing achieve this to a certain extent and allow the movement of water vapour by diffusion and mass transfer. Many forms of specialized clothing, however, have to be made from impermeable fabrics, as, for example, water-proof clothing, and the exchange of saturated microclimate air for

'Now at the Department of Mathematics, University of Surrey, Guildford ambient air has to be achieved by suitable garment designs which allow air to move in and out at garment openings. The problems involved in selecting the best design for microclimate air turnover lie to a large extent in measuring or obtaining some indications of the air exchange. This is normally done indirectly by physiological tests involving long expensive procedures beyond the resources of most laboratories concerned with the development of industrial clothing. For this reason clothing assessment has remained largely the prerogative of university and Government laboratories.

It is apparent, therefore, that a method which can quickly and simply measure the rate of exchange between the ambient and microclimate air would be of considerable use in the development of specialized clothing.

For a number of years now the rate of air exchange in rooms has been determined by trace gas dilution techniques, and the following account describes such a technique developed for the study of clothing microclimate air exchange and the mathematical 
treatment of the data. Carbon dioxide was originally tried as the trace gas but it proved unsuitable as it 'fell' out of the clothing even at low concentrations. Nitrogen was therefore used to dilute the oxygen in the microclimate and the ensuing build-up of oxygen to the atmospheric level followed.

\section{Garments tested}

Four studies were made of a wide range of garments.

\section{First study}

Five garments were tested (for design features see Fig. 1).

1. A commercially available bibbed trouser and jacket duck suit design (DS) which was used as a standard. This garment was a loose one with no constriction at the wrist, ankles or waist and is recognized as a comfortable garment. The material was a PVC-coated cotton.

2. A bibbed trouser and jacket design, tighter fitting and with elastication at the ankles and wrist.

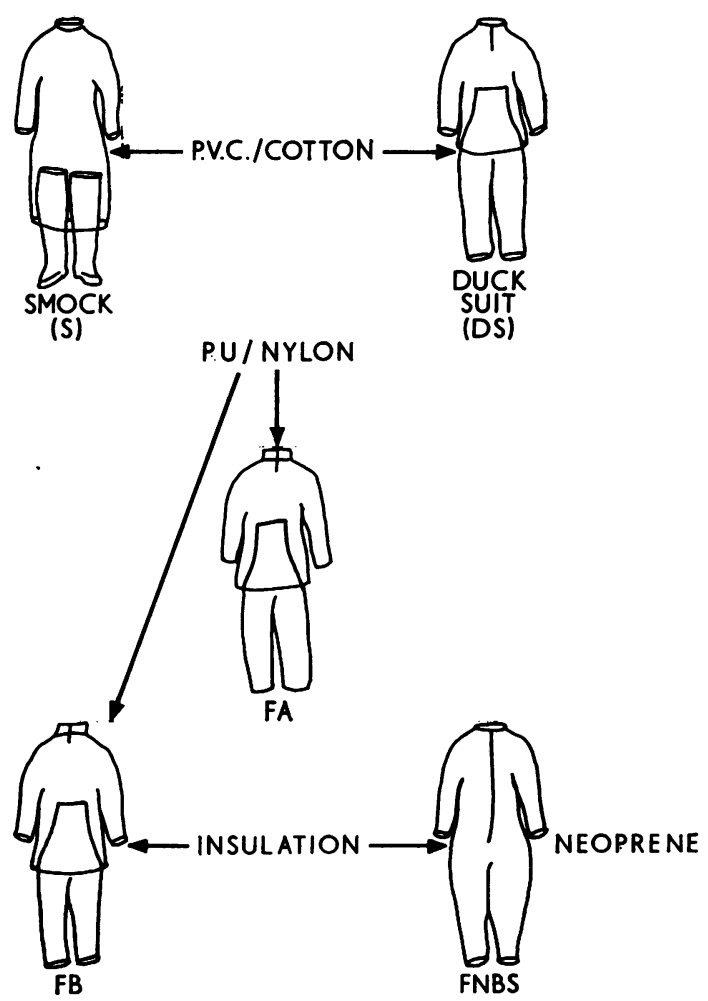

FIG. 1. Salient design features of five of the test garments illustrated diagrammatically. Only garment FA had elasticated wrists and ankles. The insulation in FB was a 2 $\mathrm{mm}$ thick layer of open-celled foamed plastic and in the FNBS $4 \mathrm{~mm}$ of foamed neoprene.
The outer material was a polyurethane-coated nylon which was lined with a similar material. This garment is referred to in the tables and text as FA.

3. An identical design to No. 2 but lined with a foamed back scrim $2 \mathrm{~mm}$ thick, which provided additional insulation. The cuffs and ankles were not elasticated. This garment is referred to as FB.

4. A typical fisherman's smock (S) made from a PVC on cotton material and worn with thigh boots.

5. A one-piece garment similar to a boiler suit in design made out of $4 \mathrm{~mm}$ thick foamed neoprene (FNBS No. 1). Circulation of air was partially restricted at the ankles and wrists and the zip down the front was virtually air tight.

\section{Second study}

In the second study the duck suit (DS) and foamed neoprene boiler suit (FNBS No. 1) were used with the following additional garments:

6. A redesigned and lined duck suit (LDS No. 1) constructed from a heavier gauge PVC-coated cotton with a lining material of impermeable polyurethanecoated nylon and between the two layers a $2 \mathrm{~mm}$ thick layer of foamed plastic.

7. A garment of identical design but made from a lighter fabric (LDS No. 2).

8. A foamed neoprene boiler suit with design modifications to improve mobility and constructed from $3 \mathrm{~mm}$ thick material (FNBS No. 2).

The underclothing worn in both studies was identical for all the garments apart from the foamed neoprene suits and consisted of woollen serge trousers, cotton pants, vest, and shirt and woollen pullover and socks. The neoprene suits were worn with cotton trousers, vest, and shirt.

\section{Third study}

In this study chemical-resistant garments were evaluated. Chemical-resistant clothing is often impermeable and careful design is needed to achieve thermal comfort. A number of PVC-coated chemical proof garments were therefore tested to determine if the trace gas technique could identify the influence of various design features. The garments tested in the third study were:

1. A one-piece combination suit with a zip and buttoned flap down the front and press stud fasteners at the wrists and ankles. The suit was worn with wellingtons and the cuff and trouser bottom openings were restricted with the press stud fasteners. A vest, shirt, pants, socks, and cotton trousers were worn under this and the following garments.

2. A bib and brace trouser overall worn with a hip length jacket with no front or rear opening (referred to by the manufacturers as a jumper). The jumper had a vent across the back. When tested the neck of the jumper was fastened to form a tight fit. Shoes were worn with this and succeeding garments. 
3. The above assembly was also tested with the jumper vent sealed.

4. Trousers, elasticated at the waist and with press stud fasteners at the trouser bottoms, worn with the jumper.

5. As above, but with the vent in the back of the jumper sealed.

6. Bib and brace trouser overall alone.

\section{Fourth study-permeable clothing}

It was considered that the possibility of using the trace gas technique with conventional clothing should be assessed and this comprised the fourth study. The two clothing assemblies tested consisted of cotton pants and vest, a shirt, and a woollen worsted lounge suit and then the same again with a cotton gabardine raincoat worn over the suit. The assemblies were tested over a range of wind speeds with the subject sitting on a stool, back to the wind. Two humidities were used, $25 \%$ and $>95 \%$ relative humidity, at an air temperature of $20^{\circ} \mathrm{C}$.

\section{Work routines}

In the first and second studies the subject hauled on a rope to lift a weight up one meter and then lowered it, repeating the movement 12 times a minute. For the third study the subject walked about the wind tunnel at 96 steps per minute.

The influence of different types of work on the air exchange rate was studied in the lined duck suit (LDS No. 1) which was fitted with wrist seals. Five different work routines were studied in a wind speed of $210 \mathrm{ft} / \mathrm{min}(1.07 \mathrm{~m} / \mathrm{sec})$. The work routines were walking, stepping on and off a $1 \mathrm{ft}(0.3 \mathrm{~m})$ stool 12 times a minute, lifting a weight from the floor to bench height and then putting it back down again 12 times a minute, raising and lowering the arms about 30 times a minute, and a routine called fish handling which consisted of picking up blocks of wood from the floor and throwing them into a dustbin at a distance of $6 \mathrm{ft}(1.8 \mathrm{~m})$ and to one side. A lift, turn of the trunk, and throw were therefore involved in the movement; the subject was facing across the air stream in this last routine and into it in the others.

\section{Gas sampling and distribution system}

Separate systems were used for sampling the microclimate and feeding in nitrogen (Fig. 2). The sampling system consisted of two sets of $1 \mathrm{~mm}$ i.d. PVC tubes, one set sampling the trunk, the other the legs. In each set the tubes were of the same length and only opened at the end. The leg harness consisted of four tubes, all going to one leg, which withdrew samples from the back and front of the thigh and calf. The trunk harness consisted of six tubes which sampled from the forearm, arm, chest, abdomen, scapula, and lumbar region. The tubes in each harness were brought together into manifolds which were mounted on the subject and a single tube, which was connected to each manifold in turn, was then connected with the pump and gas analyser.

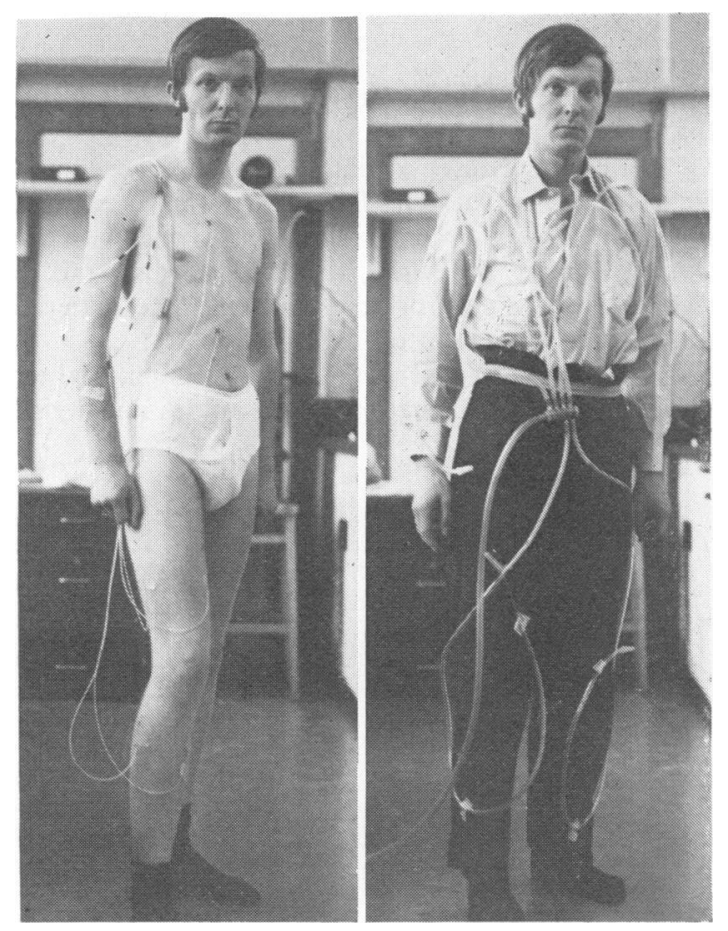

FIG. 2. Shown in position on the subject are the sampling tubes next to the skin and the nitrogen supply system which is placed between the outer protective garment and the underclothes.

Nitrogen was fed into the microclimate by one harness which consisted of six tubes of equal length emerging from a manifold at waist level, one tube going to each leg and arm and one each to the front and back of the trunk. The tubes were perforated with a double row of $1 \mathrm{~mm}$ holes at $4 \mathrm{~cm}$ intervals. Using this harness it was possible to introduce nitrogen more or less evenly throughout the microclimate.

It is important that the sampling harness, unlike the nitrogen supply harness, samples only from the open end of the tubes as the use of tubes perforated with holes along their length leads to tube dilution curves being introduced as a complication. The sampling harnesses were strapped directly on to the 
skin and the nitrogen harness was placed between the outer protective garment and the under clothing. Samples were withdrawn from the microclimate at $0.5 \mathrm{l} / \mathrm{min}$ and analysed by a type OA 137 Servomex oxygen analyser, the output of which was fed into an ultraviolet recorder.

\section{Procedure}

A wind speed of $325 \mathrm{ft} / \mathrm{min}(1.65 \mathrm{~m} / \mathrm{sec})$ was used in the first study, 210 and $450 \mathrm{ft} / \mathrm{min}(1.07$ and $2.3 \mathrm{~m} / \mathrm{sec})$ in the second study, and $180 \mathrm{ft} / \mathrm{min}(0.92 \mathrm{~m} / \mathrm{sec})$ in the third.

After dressing, the subject entered the wind tunnel and was connected to the nitrogen supply and sampling tubes. Nitrogen was then fed into the microclimate until the oxygen percentage had dropped to about $15 \%$, at which point the nitrogen was turned off and the subject started a simple rope hauling task which was maintained until the oxygen returned to atmospheric level. The procedure was repeated three times on the trunk and trousers of each garment. The ultraviolet traces were analysed by measuring the height of the curve above a selected base line (Fig. 3) at 4-second intervals, 12 to 17 measurements normally being made.

The data on the trunk or trousers of a particular garment thus consist in the main of three runs each with about 17 readings at 4-second intervals.

The model describing the time behaviour of the oxygen concentration is derived and discussed in an Appendix to this paper. It predicts that $p(t)$, the proportion of oxygen in the gas content of the suit at time $t$, rises on a curve of exponential form towards a final value of about $0 \cdot 21$, the atmospheric level. The experimental points are fitted extremely well by this model. As the experiments were conducted in a climatic chamber to which nitrogen was being added, the oxygen concentration outside the garment varied slightly between runs. This variation was apparent in the initial data plots and so the model was made to cope with such variation by allowing the parameters p0 and $p_{1}$ (see Appendix equation (1)) to vary between runs. The parameter $r$, which will be called the exchange rate, determines the rate at which the curve approaches stability and may be regarded as a single measure of speed of air exchange in the garment. The model was fitted to the data by non-linear least squares.

Having estimated the exchange rate of the model, each run is separately plotted out by the computer together with its fitted curve to enable a visual check for anomalies to be made. Other information is also computed, such as the parameter covariance matrix (from which the standard errors of the parameters may be computed), the half-lives of the curves, and confidence limits for the fitted model.

When it is decided that the curves fit the data adequately the exchange rate values for different garments may be compared by ranking them from high to low and testing for significant differences (cf Tables 1 and 2).

\section{Results}

Occasionally the dilution curves (Fig. 3) show irregular changes in oxygen concentration and this was attributed either to actual changes in exchange rate of short duration or to the shunting of the microclimate air around the garment during some body movements. In general the curves are good and fit the model well (Fig. 4).

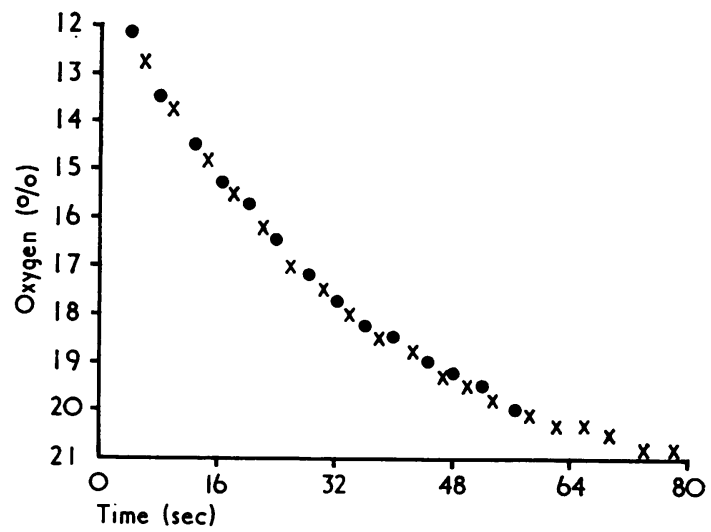

FIG. 4. Combined plot of standardized data from three runs $(O)$ together with the fitted model $(x)$. The standardized data points $(O)$ are at 4-second intervals.

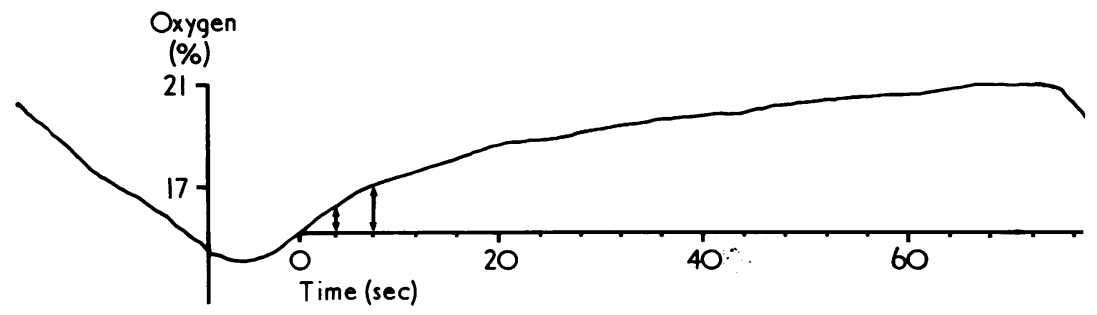

FIG. 3. A typical trace showing the initial dilution of the oxygen followed by its increase in concentration back to the atmospheric level. The data are extracted by measuring the height of the curve above a base line at 4 -second intervals as indicated. 


\section{First study}

The values of the exchange rate for each garment in the first study are given in Table 1 . Table 2 represents the findings indicating where significant differences occur between garments.

\section{Second study}

The exchange rates for the five suits in the second study are illustrated in Figure 5.

\section{TABLE 1}

EXChANGe RATES AND STANDARd ERRORS FOR Five Garments Tested in a Wind SpeEd of $325 \mathrm{ft} / \mathrm{min}$, $(1.65 \mathrm{~m} / \mathrm{sec})$ WITH THE SUBJECT DOING THE HAULING TASK

\begin{tabular}{|c|c|c|c|c|}
\hline & Garmert & $\begin{array}{c}\text { Exchange } \\
\text { rate }\end{array}$ & $\begin{array}{c}\text { Standard } \\
\text { error }\end{array}$ & $\begin{array}{c}\text { Rank order } \\
\text { of exchange } \\
\text { rate }\end{array}$ \\
\hline $\begin{array}{l}\text { Subject } \\
\text { G. W.C. } \\
\text { FNBS } \\
\text { FNBS } \\
\text { FB } \\
\text { FB } \\
\text { FA } \\
\text { FA } \\
\text { DS } \\
\text { DS } \\
\text { Smock }\end{array}$ & $\begin{array}{l}\text { Trunk } \\
\text { Trousers } \\
\text { Trunk } \\
\text { Trousers } \\
\text { Trunk } \\
\text { Trousers } \\
\text { Trunk } \\
\text { Trousers } \\
\text { Trunk } \\
\text { Thigh } \\
\text { boots }\end{array}$ & $\begin{array}{l}1.0544 \\
2.0230 \\
0.8593 \\
1.8579 \\
0.9728 \\
0.8360 \\
2.7538 \\
3.7158 \\
2.1379 \\
2.9218\end{array}$ & $\begin{array}{l}1.69 \times 10^{-1} \\
1.79 \times 10^{-7} \\
3.13 \times 10^{-6} \\
9.28 \times 10^{-2} \\
7.82 \times 10^{-2} \\
1.37 \times 10^{-1} \\
1 \cdot 19 \times 10^{-1} \\
1.77 \times 10^{-1} \\
2.36 \times 10^{-12} \\
1.24 \times 10^{-1}\end{array}$ & $\begin{array}{r}4 \\
9 \\
2 \\
7 \\
3 \\
1 \\
11 \\
14 \\
10 \\
12\end{array}$ \\
\hline $\begin{array}{l}\text { Subject } \\
\text { J.H. } \\
\text { FB } \\
\text { FB } \\
\text { FA } \\
\text { FA } \\
\text { DS } \\
\text { DS }\end{array}$ & $\begin{array}{l}\text { Trunk } \\
\text { Trousers } \\
\text { Trunk } \\
\text { Trousers } \\
\text { Trunk } \\
\text { Trousers }\end{array}$ & $\begin{array}{l}4 \cdot 7582 \\
1 \cdot 7659 \\
1 \cdot 9272 \\
1 \cdot 7080 \\
4 \cdot 4887 \\
3 \cdot 3801\end{array}$ & $\begin{array}{l}3.07 \times 10^{-1} \\
1.51 \times 10^{-1} \\
1.28 \times 10^{-1} \\
1.29 \times 10^{-1} \\
1.86 \times 10^{-1} \\
2.37 \times 10^{-1}\end{array}$ & $\begin{array}{r}16 \\
6 \\
8 \\
5 \\
15 \\
13\end{array}$ \\
\hline
\end{tabular}

Three runs were made for each suit (trunk and trousers) in each of two wind speeds, and the figure shows the values of the exchange rate $r$ pooled over sets of three runs. It appears that air exchange is generally faster for the trunk than for the trousers and increases with wind speed. To examine these and other questions posed by the diagram, an analysis of variance was performed on $r$, the three main factors being suit, body half (trunk or trousers), and

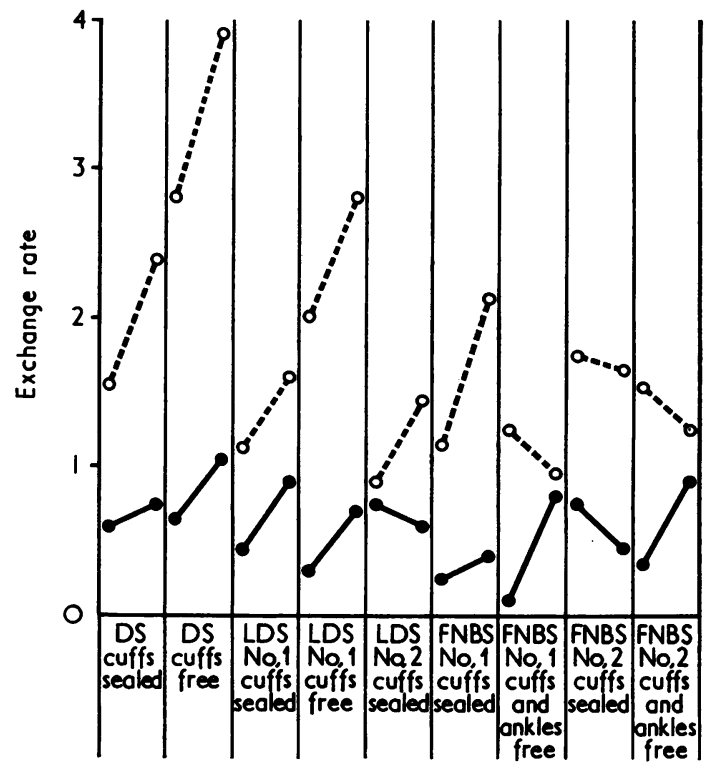

FIG. 5. The exchange rates obtained in the second study presented graphically. The continuous lines refer to the trousers and the broken lines to the trunk. The point on the left corresponds to a wind speed of $210 \mathrm{ft} / \mathrm{min}$ and the point on the right to $450 \mathrm{ft} / \mathrm{min}$. The trouser leg bottoms are sealed unless stated otherwise.

TABLE 2

Garments arranged in Ascending Order of Exchange Rate

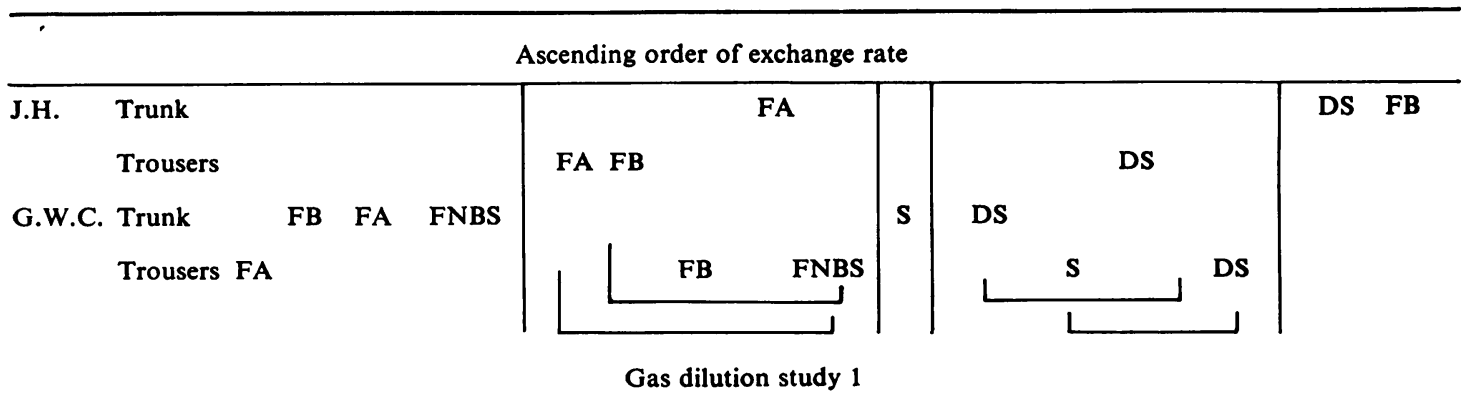

Subject, garment and part of garment are indicated on left. Vertical lines separate significantly different groups and significant differences within groups are indicated. 
TABLE 3

ANALyses of Variance of Exchange Rate for TrunK and Trousers SeParately

\begin{tabular}{l|r|c|c}
\hline \multicolumn{1}{c|}{ Source } & d.f. & m.s. & \multicolumn{1}{c}{$F$} \\
\hline Trunk & & & \\
Suits & 8 & $3 \cdot 10749$ & $5145 \cdot 7(7 \cdot 1)$ \\
Wind speed & 1 & $2 \cdot 39385$ & $3964 \cdot 0(5 \cdot 5)$ \\
Interaction & 8 & $0 \cdot 43794$ & $725 \cdot 2$ \\
Error & 36 & $0 \cdot 0006039$ & \multicolumn{1}{|c}{-} \\
\hline
\end{tabular}

\begin{tabular}{l|r|l|c}
\hline \multicolumn{1}{c|}{ Source } & d.f. & m.s. & \multicolumn{1}{c}{$F$} \\
\hline Trousers & & & \\
Suits & 8 & $0 \cdot 11103$ & $74 \cdot 5(0 \cdot 7)$ \\
Wind speed & 1 & $0 \cdot 89143$ & $6027 \cdot 2(5 \cdot 4)$ \\
Interaction & 8 & $0 \cdot 16623$ & $112 \cdot 4$ \\
Error & 36 & $0 \cdot 001479$ & \multicolumn{1}{|c}{-} \\
\hline
\end{tabular}

m.s. = mean square; d.f. $=$ degrees of freedom; $\mathbf{F}=$ variance ratio

wind speed (Table 3). As each cell in this analysis contains three estimates of $r$ (from three experimental runs), a between replicates variance is available and this is extremely low. The implied high reproducibility of the experiment makes every comparison significant in the analysis of variance, in particular the body half factor and its interactions with other factors. Because of the difference between the body halves it was decided that treating trunk and trousers separately would give a more comprehensible picture and the two analyses are shown in Table 3.

For both trunk and trousers, the interaction term is high so that the effect of wind speed is different on different suits. Referring to Fig. 5, this means that the trunk lines (broken) for different suits cannot be considered parallel, and similarly for the trousers. The figures in parentheses in Table 3 are ratios of mean squares to the interaction mean square. Their interpretation for trunk is that in spite of the interaction, the higher wind speed generally produces a higher exchange rate, and overall differences between suits are still large. For the trousers, wind speed again has an effect on the rate but the suit differences are lost.

All of this is evident from a study of Figure 5. Assessing differences between selected pairs of individual points on the diagram, the standard errors are 0.020 (trunk) and 0.031 (legs).

\section{Third study}

The results obtained on the chemical proof garments are plotted in Figure 6. The trousers are considered first. The exchange rates for the combination suit and the bib and brace overall when worn with the jumper are very similar, indicating that little is achieved in the way of increased ventilation of the legs by changing from a one-piece to a two-piece design. Elastication of the trousers at the waist (e) lowers the rate of air exchange, and removal of the jumper from the bib and brace trousers (d) increases its rate of exchange. The trunk of the one-piece combination (a) and the jumper (b) have similar rates of exchange, that of the jumper being increased

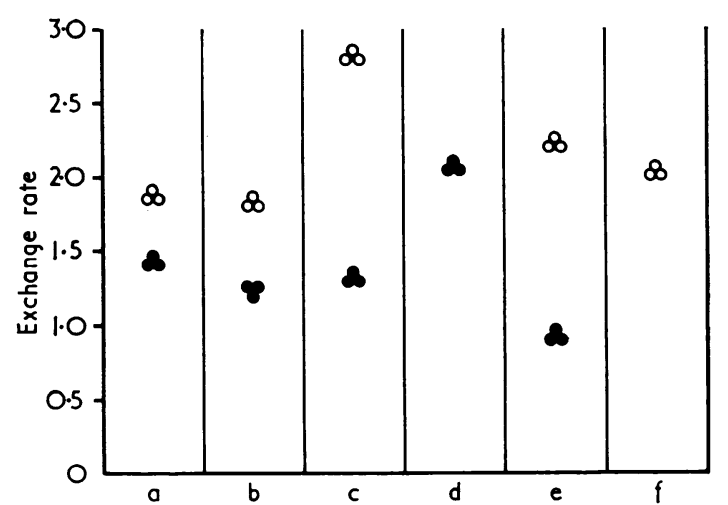

FIG. 6. The three exchange rates of each batch for the chemical proof garments. In order they are: (a) onepiece combination suit; (b) bib and brace trousers with vented jumper; (c) bib and brace trousers with unvented jumper; (d) bib and brace trousers; (e) elasticated trousers and vented jumper; (f) elasticated trousers and unvented jumper: trousers (O); jumper (O).

slightly when worn with elasticated trousers which presumably restrict mixing between the two haives of the garment. When the back vent in the jumper is sealed (f) there is a small drop in the exchange rate. There is one set of anomalous results in which the exchange rate of the jumper is considerably increased by sealing the back vent (c). There is no obvious explanation for this from the records of the experiments. The sealing of the vent with adhesive tape may have altered the bellows action or the subject may have behaved in a slightly different way. A malfunction in the sampling harness is not considered to be very likely as the sealed back vent runs were done first and then the adhesvie tape was removed for the open vent runs.

\section{Fourth study}

The exchange rates obtained at the different wind speeds are plotted in Figure 7. The trace gas technique appears to be applicable to permeable clothing and 


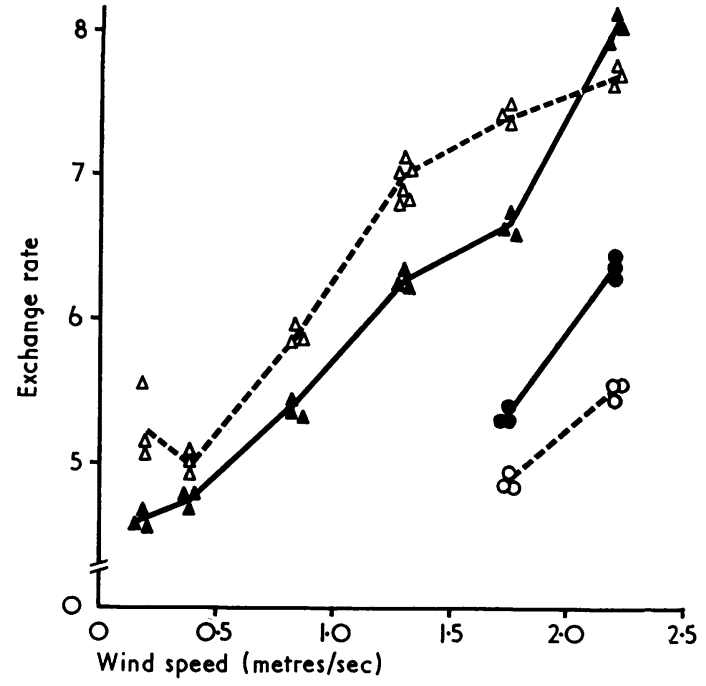

FIG. 7. The exchange rates for the three runs in each batch are plotted for the underclothes and lounge suit $(\triangle)$ and with a raincoat worn on top $(O)$ against wind speed for conditions of $25 \% \mathrm{RH}$, continuous lines, and $95 \%$ RH, broken lines.

is able to identify changes in permeability as a result of adding a raincoat to the assembly and the influence of windspeed. It would appear that the permeability of this type of clothing may be influenced by the relative humidity of the air. The expansion of the fibres and reduction in permeability of closely woven fabrics of the type the raincoat is made from is well known. The increase in permeability of the woollen suit may be due again to changes in the dimensions of fibres with humidity but because of the different weave they act to open up the fabric; certainly the feel of the suit material changed considerably on exposure to the high humidity.

\section{Work routines}

The exchange rates for the trunk of the lined duck suit No. 1 with the six different forms of work are shown diagrammatically in Figure 8. Each type of work influences the rate at which the microclimate air is exchanged, those resulting in pronounced movement of the garment having the greatest effect.

\section{Discussion}

The technique of diluting the oxygen in the microclimate and then following its return to the atmospheric value is technically very easy and, with the work routines used in this study, shows a high reproducibility and resolving power. Using separate

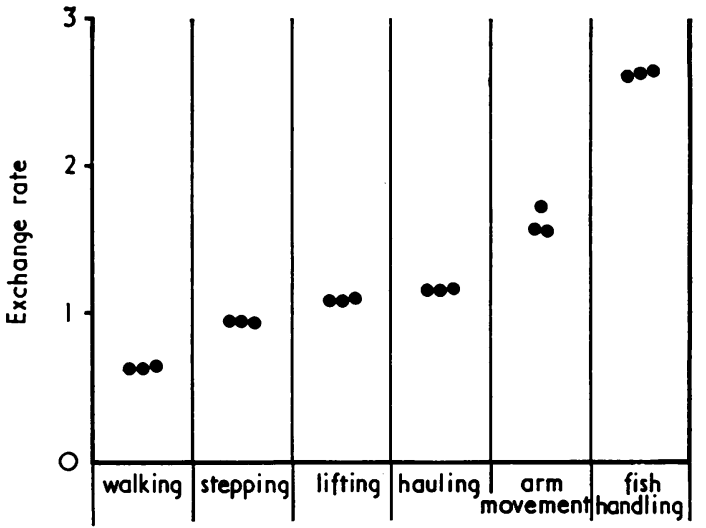

FIG. 8. Change in exchange rate as a result of changes in the work routine. The exchange rate for the individual runs in each batch is plotted for the trunk of the lined duck suit No. 1 for six different work routines. Cuffs and ankles were sealed.

sampling systems, it is possible to study the trunk and trousers as two separate parts of the garment. In some garments distinct differences in the exchange rates for these two regions can be observed, so indicating where design changes may be required.

The speed with which the garments can be studied is very high compared with standard physiological procedures. In order to demonstrate physiologically differences between garments in the rate at which sweat is evaporated from the microclimate, experiments lasting about 2 hours per garment run are required. A trace gas run on both trunk and legs takes about 6 minutes.

Two garments in the first study (FA and FB) were a tight fit. It therefore appeared worth while to test them on a slimmer subject (J.H.) to determine if variations in 'fit' could be identified. The results as illustrated in Table 2 show that the fit of a garment can have a significant influence on the rate at which the microclimate air is exchanged. When the results obtained on G.W.C. are compared with those from J.H., with the exception of non-significant changes in the trousers of F.B. and D.S., all the exchange rates increase significantly when the garments are worn by a slimmer subject.

The garments which are open at the wrists, ankles, and waist (DS and S) have significantly higher exchange rates than those of the other garments. The duck suit and smock also differ significantly, the duck suit having the higher exchange rates, possibly because of the opening at the ankles and the smaller overlap between trunk and legs. At the other extreme the trousers of FA had the lowest rates of exchange. Again this is what might be expected because of the elastication at the ankles and wrists. 
The air exchange in the trunk of the FNBS occurred more or less at the same rate as in FA and FB but the trousers were nearer to the FB trousers. This may indicate that the FNBS trousers were not a tight fit over the boots and allowed air exchange to take place.

The results of the first study showed that one of the main features of the fisherman's conventional protective clothing, the smock and duck suit, is the high rate of air exchange existing between the microclimate and ambient air. It is almost certainly this feature which enables these impermeable garments to be used by trawler fishermen at an activity level graded as moderate to hard work without becoming soaked in sweat. When other clothing designs are used with improved waterproof qualities, i.e., cuff and ankle seals (FA), the air exchange rate constant is significantly reduced. The second series of tests was done to compare new designs of the duck suit as well as the foamed neoprene boiler suit, with and without wrist seals, against the original duck suit, this time with the ankles sealed, to determine the loss in ventilation as a result of the design changes. The lined duck suit No. 1 behaves in essentially the same way as the standard duck suit but the addition of the buoyancy aid layer has reduced the rate of air exchange. The lined duck suit No. 2 jacket also behaves in essentially the same way as the standard.

It is apparent from these tests that the incorporation of cuff seals into the jacket has a pronounced effect on its microclimate air exchange characteristics. In addition other aspects of the garment design are also influencing the exchange rate of the jacket adversely.

Considering the one-piece foamed neoprene garments, it is surprising to find that their rates of exchange are very similar to those of the cuff-sealed duck suits and that the presence or absence of cuff seals does not appear to have a great influence on the exchange rates. Wind also appears to have little effect on the microclimate air turnover, apart from the legs where removal of the wrist seals increases the exchange rate. It is possible, of course, that in this one-piece design air tends to enter at the ankles and this is reduced by wrist seals. If this were to happen then it is quite possible that the trunk would show a reduced rate constant as air containing trace gas could be moving into the trunk from the legs and not fresh ambient air.

Although the exchange rates for the foamed neoprene boiler suit are very similar to those of the redesigned duck suits, this cannot be interpreted as indicating similar rates of mass exchange as the microclimate volumes may differ.

The half-life of the trace gas in the microclimate

is given by the formula $\frac{0.6931}{r}$ (where $r$ is the rate constant), and the mass exchange rate is equal to $r$ times the microclimate volume. In the case of the FNBS trunk which has an exchange rate of 1.0544 (Table 1) the half-life is $0.6931 / 1.0544=0.66 \mathrm{~min} \bumpeq$ $40 \mathrm{sec}$ and the mass exchange rate, assuming a microclimate volume of 15 litres for the trunk, is $1.0544 \times$ $15=15 \cdot 836 \mathrm{l} / \mathrm{min}$. A method for estimating clothing microclimate volumes will be the subject of a future communication.

The study of the chemical proof clothing showed again that there could be little difference between a one- and a two-piece garment in the rate at which air is exchanged under the test conditions employed in these studies. The back vent on the jumper is of doubtful value but the anomalous results obtained with the sealed back vent indicate the sensitivity of the technique and its potential value in studying the finer details of design and use. The possible wide applicability of the technique is indicated by the study on conventional clothing and the effects of different work routines.

From this study it appears that a trace gas technique is eminently suitable for measuring the rate at which clothing microclimate air is exchanged for ambient air. The technique has a high resolving power, enabling the effect of design changes, sizing, wind velocity, and work routines on the exchange of air to be studied. The method is very quick and cheap compared with standard physiological procedures and enables the different compartments of the microclimate to be studied.

\section{APPENDIX \\ Derivation and discussion of model}

Let the total amount of gas inside the suit be $V_{T}$ litres; this is assumed to be constant in time. Also let the proportion of oxygen inside the suit at time $t$ minutes after the start of the experimental run be $p(t)$, the other $V_{T}[1-p(t)]$ litres being chiefly nitrogen.

The mixture of oxygen and nitrogen inside the suit is exchanged during a run with air from outside which contains a proportion po (approximately $0 \cdot 21$ ) of oxygen. We assume that the rate of this exchange is constant in time and that the gas mixture inside the suit is homogeneous at all times. Gas is also drawn off for sampling at a constant rate. The sum of these two rates will be denoted by $r$ and called the exchange rate, so that $\mathbf{r V}_{T}$ litres of gas per minutre are exchanged between the suit and the air.

It may be shown that $p(t)$, the suit oxygen concentration at time $t$, satisfies the differential equation

$$
\frac{d p}{d t}=r[p o-p(t)]
$$

which integrates to

$$
p(t)=p o-p_{1} \exp (-r t)
$$

This is an exponential process in which po is the asymptote (eventual value of $p(t)), p_{1}$ is a constant such that the difference po $-p_{1}$ is the initial value of $p(t)$ at 
time $t=0$, and $r$ (the exchange rate) is the exponential decay parameter of the curve.

It must be mentioned that the meter reading (say y) is not precisely equal to, or proportional to, $p(t)$; in fact there is a short time lag involved for which a reasonable description is that $y$ approaches $p(t)$ at a rate proportional to its distance from $p(t)$. Investigation showed this to have the effect of introducing a second exponential term into equation (1). However, this second exponential decays much faster than the first, and has become negligible in comparison with the first by the time readings start at some time after $t=0$. Thus this aspect was ignored.

Some preliminary fitting of equation (1) showed that the estimated value of po was in many cases slightly, but by a statistically significant amount, lower than its expected value, around $\mathbf{0} \cdot 21$. The most plausible explanation was that there was a pocket, or pockets, of nitrogen in the suit remote from the sampling area and exchanging gas with the rest of the suit relatively slowly. The effect of this on the model was investigated and led to the differential equation

$$
\left(\frac{V_{\mathbf{T}}-V_{\mathbf{P}}}{\mathbf{V}_{\mathbf{T}}}\right) \frac{\mathrm{d}^{2} \mathrm{p}}{\mathrm{dt}^{2}}+(\alpha+\beta) \frac{\mathrm{dp}}{\mathrm{dt}}+\alpha \beta \mathrm{p}=\text { po } \alpha \beta,
$$

where $V_{P}$ is the gas content of the pocket in litres, $\alpha V_{T}$ is the rate of exchange (litres/minute) of gas between the suit and the air, and $\beta V_{P}$ is the rate of exchange of gas between the pocket and the rest of the suit.

This leads to a model involving two exponentials

$$
p(t)=p o-A \exp \left(-r_{1} t\right)-B \exp \left(-r_{2} t\right)
$$

where $A, B$ are constants of integration, and $r_{1}, r_{2}$ are simple functions of $\alpha, \beta$.

If $V_{P}$ is small compared with $V_{T}, r_{1}$ and $r_{2}$ are nearly equal to $\alpha$ and $\beta$ respectively and can therefore be roughly identified as the component rates due to suit-air exchange and pocket-rest of suit exchange.

Equation (2) was fitted to a few sets of data but gave little better fit than (1). An explanation might be that one pocket is too simple a description. For instance, the folds in the trouser leg might, in effect, form a chain of pockets exchanging gas all along the line and eventually with the air. It was decided to use equation (1) in the analysis on the following grounds:

(a) examination of residuals from model (1) gave no evidence of systematic lack of fit;

(b) use of model (2), or more complicated versions, is likely to give small return for much calculation and computing effort;

(c) interpretation of results is straightforward for model (1) since it involves a single parameter $r$ which is identified as the exchange rate of gas between the suit and the air.

The authors would like to thank Professor J. S. Weiner for the fruitful discussions which led to this study.

Received for publication December 15, 1971. 